\title{
REDES SOCIAIS, CONHECIMENTO E INOVAÇÃO LOCALIZADA
}

\section{Maria Inês Tomaél}

\section{Resumo}

O processo de inovação recebe influência de seu meio, o que o torna dependente da interação social, que é preponderante para seu crescimento e solidificação. As redes sociais, estruturadas pelas interações entre atores, propiciam o compartilhamento da informação e a construção do conhecimento determinantes para o desenvolvimento de inovações. Considerando esses elementos, este estudo tem como objetivo distinguir experiências de caráter localizado da inovação e do conhecimento em um consórcio de exportação de móveis. Para tanto, a metodologia empregada foi a Análise de Redes Sociais (ARS), que mapeia as interações entre atores, enfatizando medidas e fluxos de informação entre eles. Os resultados indicam que as redes sociais permeiam o compartilhamento da informação que levam a apropriação do conhecimento e sua adaptação para distintas realidades e que esse processo ocorre entre as empresas participantes do consórcio no âmbito da gestão de processos. Tais empresas desenvolvem procedimentos similares para a inovação de gestão. Em virtude desse fato, consideramos que na rede social

\section{INTRODUÇÃO}

As redes sociais, formadas por estruturas ramificadas, estão em constante movimento. Dependendo do projeto que as sustenta, atores despontarão como importantes em determinados momentos, porque são compostas por sujeitos ligados pelo compartilhamento de recursos e idéias em do consórcio a inovação de gestão é localizada.

\section{Palavras-Chave}

Redes Sociais; Compartilhamento da Informação; Inovação Localizada. comum. São assim concebidas e materializadas no contexto das relações e ações sociais coletivas, centrando-se nas pessoas e em suas práticas. Desse modo, elas podem ser percebidas e estudadas como uma forma de representar e entender a composição e o funcionamento da estrutura social. 
A análise das redes sociais pode ser realizada por diferentes prismas. Em virtude desse fato, muitas áreas do conhecimento a empregam para o estudo de particularidades de uma especialidade. $\mathrm{Na} \mathrm{Ci}$ ência da Informação, a abordagem das redes sociais tem sido direcionada para múltiplos domínios, mas com maior ênfase tem sido aplicada tanto nos estudos de produção científica quanto nos que tratam dos fluxos/canais de informação e conhecimento.

Neste trabalho, a aplicação da análise de redes sociais está associada aos fluxos da informação com o objetivo de distinguir experiências de caráter localizado da inovação e do conhecimento.

A tônica deste trabalho está atrelada à crença de que a construção do conhecimento e sua aplicação no setor produtivo levam à inovação de produtos e processos, que, quando desenvolvidos e aplicados em espaços geográficos limitados, integram um sistema local de inovação e incorporam características do contexto sociocultural em que estão inseridos.

É por meio das interações entre atores empresariais que um sistema de inovação se desenvolve e fortalece baseado em parâmetros enriquecidos pelo ambiente sociocultural que os acolhe e pelo conhecimento que permeia as relações. Os sistemas de inovação são articulados pela interação de diferentes agentes na produção e difusão de conhecimentos para o alcance de resultados econômicos. A proximidade e a interação entre esses agentes, próprios dos sistemas de inovação, podem levar as empresas a inovações similares, de âmbito local - a inovação localizada.

A inovação localizada ocorre pela apropriação do conhecimento, construído por meio do compartilhamento de experiências e, por isso, é mais profícuo quando a interação, entre os atores, é constante. Quando há partilha de experiências e práticas, estas se tornam comuns em alguns domínios e podem se expandir. Quando este conhecimento interage com o de outros indivíduos, ele pode completar-se e até aprimorar-se. Com base nessas assertivas, pode-se afirmar que a construção coletiva do conhecimento encontra o seu melhor ambiente nas redes sociais locais.

Para estudar e identificar novas experiências, de caráter localizado, que tenham sido socializadas a partir do conhecimento desenvolvido no decorrer das atividades em um consórcio para exportação de móveis, empregamos a metodologia própria para estudar as redes sociais: "Análise de Redes Sociais (ARS)". Essa metodologia possibilita o delineamento da estrutura social por meio de uma rede e, assim, permite proceder a sua análise por meio de ma- 
trizes ou da imagem gráfica. No diagrama da rede social, atores são representados por "nós" e suas relações por linhas que as demonstram.

A ARS investiga os padrões de relacionamento com base nas interações e procura identificar, por meio de indicadores, os efeitos dessas interações nos atores e nas organizações. Neste estudo, as interações foram pesquisadas tendo como referência principal o compartilhamento da informação. Para tanto, entrevistamos 25 atores, de 17 indústrias moveleiras - situadas em um Pólo Moveleiro no sul do Brasil -, que formaram uma parceira para exportação de móveis, por meio da criação e manutenção de um Consórcio de Exportação.

A análise das entrevistas foi feita em dois momentos: no primeiro, os dados foram analisados quantitativamente pelo $\mathrm{U}$ cinet $^{1}$, software desenvolvido por Borgatti, Everett e Freeman (2002), que mapeia a rede e possibilita o estudo das ligações dos atores pelos seus padrões de relacionamento. No segundo, procedeu-se a uma análise qualitativa. A partir dos resultados do mapeamento da rede, empregamos a análise temática baseada em categorias, possibilitando a interpretação e a inferência das informações prestadas pelos entrevistados.
A análise possibilitou o mapeamento e o entendimento das nuances presentes na rede que se forma no âmbito desse consórcio e a distinção da experiência coletiva que demonstra 0 caráter localizado da inovação e do conhecimento.

\section{REDES SOCIAIS - ABORDAGEM TE- ÓRICA}

Uma rede social refere-se a um conjunto de pessoas (ou organizações ou outras entidades) conectadas por relacionamentos sociais, motivadas pela amizade, relações de trabalho ou troca de informação. Constitui-se da representação formal de atores e suas relações. As redes desenvolvem-se a cada contato que mantemos, provocando a construção social do indivíduo e, quando vista por suas relações, podem identificar coesões e similaridades, em ações coadunadas de indivíduos que agem como um único corpo social.

As unidades, que compõem esse corpo social, representam as redes sociais e constituem um conjunto de relações responsáveis pelo compartilhamento da informação na rede. As relações mantidas na rede são tão imbricadas que, na maior parte das vezes, é difícil precisar como começaram ou com quem.

Para Marteleto (2001, p. 72), rede pressupõe um "sistema de nodos e elos; uma estrutura sem fronteiras; uma comuni- 
dade não geográfica; um sistema de apoio ou um sistema físico que se pareça com uma árvore". Respaldada por esse conceito, a autora entende rede social como "um conjunto de participantes autônomos, unindo idéias e recursos em torno de valores e interesses compartilhados".

Uma rede social é uma representação formal de atores e suas relações. Delinear a estrutura social por meio de uma rede possibilita a sua análise mediante matrizes ou imagem gráfica. No diagrama da rede social, atores são representados por nós e suas relações por traços que as demonstram.

As estruturas hierárquicas, no âmbito das redes sociais, perdem sua função e os elos informais e as relações são valorizadas. "Hoje o trabalho informal em rede é uma forma de organização humana presente em nossa vida cotidiana e nos mais diferentes níveis de estrutura das instituições modernas" (MARTELETO, 2001, p. 72).

O estudo das redes coloca em evidência a realidade social e as ações dos indivíduos no espaço em que se pode configurar as redes. Isso porque, explica Marteleto (2000, p. 81), "mesmo nascendo em uma esfera informal de relações sociais, os efeitos das redes podem ser percebidos fora de seu espaço, as interações com o Estado, a sociedade ou outras instituições representativas".
Redes sociais podem variar em seu alcance, por exemplo, no seu tamanho e heterogeneidade. Quanto maior for a rede social, mais heterogêneas são as características sociais dos membros da rede e maior a complexidade na estrutura dessas redes (GARTON; HAYTHORNTHWAITE; WELLMAN, 1997).

A presença de redes sociais é um ingrediente necessário em qualquer sociedade coesa. O conceito de redes sociais foi primeiramente introduzido por Barnes em 1954 e está consolidando-se a partir de então. O emprego metafórico da idéia de rede social enfatiza que as ligações sociais de indivíduos, em qualquer sociedade, ramificam-se por meio dessa mesma sociedade. O emprego analítico da idéia de rede social especifica como essa ramificação influencia o comportamento das pessoas envolvidas na rede (MITCHELL, 1974).

Em 1972 Barnes (1972) colocou em dúvida se "redes" era apenas uma palavra de moda. E demonstrou, no mesmo artigo, que há outras instâncias em que o conceito de redes sociais é aplicado como se deve.

O autor afirma que todo indivíduo na sociedade está conectado a outros por ligações sociais que em parte reforçam e em parte provocam o conflito. A situação encontrada - ordem ou desordem - em um meio social é resultante da limitação que essas ligações impõem às ações dos indivíduos. Essa idéia também é empregada 
em redes sociais como um instrumento de análise. A idéia básica, que sustenta a metáfora da rede e a análise de redes sociais, é a de que a configuração dos elos interpessoais de alguma forma está relacionada com as ações das pessoas no seu meio.

Em uma leitura paradoxal, Kohn (1994) sustenta que a rede aproxima elementos dispersos, criando espaços intersticiais, até mesmo os mais improváveis. Estende-se por territórios e tempos diferenciados e transpõe ordens estabelecidas. Ignorando organogramas, a rede penetra no instituído e cria relações encadeadas que ultrapassam territórios e se firmam em prol de uma ação ou objetivo. Promove a circulação de bens, de informações e de pessoas, nas relações que estabelece entre os agentes que dela fazem parte.

A autora distingue o nível individual do coletivo na rede, que no seu entendimento são distintos, mas inconcebíveis um sem o outro. Todos na rede contribuem de alguma forma e também usufruem das relações que são criadas no seu âmbito, tendo liberdade em ambos os casos para contribuir individualmente e usufruir de uma construção coletiva.

A contribuição para com a rede, dos níveis individual e coletivo, está, igualmente, presente nas redes sociais que permeiam o espaço dos ambientes de negócios. Cross, Borgatti e Parker (2002) afirmam que significativos esforços têm possibilita- do, dentro das organizações, níveis hierárquicos mais tênues e com limites internos e externos mais permeáveis. A coordenação dos trabalhos ocorre, progressivamente, por meio de redes informais de relacionamento, de preferência por meio de canais fortemente prescritos por relatórios formais ou processo de trabalho detalhado. Freqüentemente, essas redes promovem na organização maior flexibilidade, inovação e eficiência, assim como qualidade de produtos ou serviços em virtude de efetivamente unir expertise.

Cross, Prusak e Parker (2002) afirmam que raramente vêem gerentes avaliando sistematicamente redes informais dentro de organizações. Os autores acreditam que as redes constituem considerável suporte dentro das organizações e são um desafio para as mudanças gerenciais que estão ocorrendo atualmente. Redes informais formam-se por ações e/ou processos que se cruzam e/ou se unem em determinados pontos de seu desenvolvimento.

Cada vez mais as redes informais tornam-se importantes para efetivar a inovação. Isto se aplica não só à colaboração dentro e entre instituições científicas e tecnológicas, mas também entre empresas cadeia produtiva - e entre empresas e consumidores.

As redes sociais fornecem às empresas um conjunto de recursos próprios, em forma de canais de acesso a conhecimen- 
tos e oportunidades e em forma de normas de valores associados com as relações sociais (CROSS; PRUSAK; PARKER, 2002).

\section{INOVAÇÃO}

\section{ABORDAGEM TEÓRICA}

O conhecimento aplicado com objetivos econômicos, normalmente, traduz-se em inovação, que implica a introdução de novidades em produtos ou processos totalmente novos ou aperfeiçoados. A consecução de uma inovação de produto ocorre quando se toma por base sua adoção pelo mercado, e a inovação de processo quando se considera seu uso efetivo no processo de produção. Pavitt (1984) esclarece esses conceitos, relacionando inovação de processo àquelas, aplicadas no mesmo setor que as produziu, e inovação de produto às aplicadas em diferentes setores.

Com características mais abrangentes, a lei de inovação (BRASIL, 2004) define inovação como a "introdução de novidade ou aperfeiçoamento no ambiente produtivo ou social que resulte em novos produtos, processos ou serviços".

O precursor da inovação, Joseph Schumpeter, já no início do século passado, salientava a importância da inovação para a economia. $O$ autor acreditava que 0 novo sempre se desenvolve ao lado do velho, cresce e o supera, o que denominou de "destruição criadora". Para Schumpeter, o processo essencial para as indústrias é a inovação e não a invenção, em sua concepção a importância dos avanços tecnológicos está na consolidação do desenvolvimento empresarial e econômico.

Valendo-se dos conceitos introduzidos por Schumpeter, muito se tem explorado a expressão inovação tecnológica. A distinção entre a inovação radical e a incremental envolve aplicações e resultados também diferentes: a radical envolve a introdução de um novo conceito no mercado e a incremental significa uma adição ou diferenciação num conceito já absorvido e aceito mercadologicamente. Muitas outras expressões foram também disseminadas para especificar os diferentes tipos de inovação, entre elas podemos destacar:

- Inovação organizacional ou de gestão refere-se à implantação de novas alterações nos processos organizacionais internos e externos à organização, incluindo os recursos financeiros, materiais e de pessoal de uma empresa;

- Inovação de mercado - está ligada ao descobrimento e inserção de produtos em um novo nicho de mercado;

- Inovação de negócio - é a estruturação ou reestruturação de uma atividade industrial, comercial ou de serviço.

Lundvall (1995), refletindo sobre os tipos de inovação, diz: se inovação é con- 
solidada pelo aprendizado, e aprendizado é uma atividade rotineira, então devemos esperar que toda atividade inovadora seja incremental, o que denotaria a direção das mudanças técnicas. Mas, continua Lundvall, devemos levar em conta o caráter incerto e que produz rupturas no processo de inovação. As regras no processo de atividades científicas são incertas e estas produzem, de tempos em tempos, resultados que não podem ser antecipados nem se estivessem sendo procurados. Incerto também é o impacto econômico de uma inovação.

Com o propósito de reunir elementos para a compreensão do processo de inovação, sintetizamos os argumentos de Cassiolato e Lastres (2000):

- A inovação e o conhecimento são tidos como elementos centrais tanto em espaços geográficos quanto nas organizações;

- A inovação é a base do processo de busca e aprendizado, influenciado pelas interações e socialmente determinado e influenciado pelo contexto organizacional;

- Os atores que participam desse processo e suas capacidades de aprendizado são determinantemente diferentes;

- Os sistemas de inovação possuem distinções significativas entre países, regiões, setores, organizações, etc., isto em função das peculiaridades do contexto local;
- A informação e o conhecimento explícito possuem, cada vez mais, plenas condições de ser compartilhados, e o conhecimento tácito, que continua sendo elemento central da inovação, possui peculiaridades locais e características próprias.

Esses elementos estão em sintonia com Fleury e Fleury (1997, p.11) que defendem a idéia de que "o conceito de inovação tem que estar profundamente imbricado no conceito de aprendizagem". Desse modo, a aprendizagem organizacional tem uma função determinante nas discussões do meio acadêmico e empresarial.

A incorporação e o adensamento do conhecimento no desenvolvimento de inovações têm acirrado a competitividade e desencadeia mudanças sintomáticas no mercado de trabalho e, ainda, disponibiliza instrumentos que podem melhorar as condições de vida.

As informações utilizadas nos processos de inovação e produção empresarial estão imbuídas de múltiplos domínios e recursos. À medida que as informações referentes a novos processos e ao contexto são assimiladas, os indivíduos constroem conhecimento, agem respaldados em experiências e, baseados em suas ações, fomentam a troca e a interação com o mundo real no qual estão inseridos. $O$ conhecimento é considerado, portanto, como um importante recurso para todas as ativi- 
dades, especialmente para a inovação. A dimensão tácita do conhecimento individual não está, geralmente, disponível, exceto quando incorporada à dimensão tácita do conhecimento coletivo, que é criado e desenvolvido dentro de muitas indústrias e organizações, e não é facilmente reproduzido. A criatividade necessária para a inovação deriva não apenas da expertise óbvia e visível, mas de reservatórios de experiências invisíveis.

Uma inovação da perspectiva do processo interativo traz dois novos elementos, de acordo com Lundvall (1995). O primeiro reflete mudança e crescimento complexos, pelo fato de a inovação envolver a criação de novos bens e novos conhecimentos. Agentes envolvidos na criação e adoção de inovações não podem, de maneira lógica, conhecer os possíveis resultados de suas atividades. O segundo elemento diz respeito a uma mudança do foco que dá origem a um processo de tomada de decisão, por meio de um processo de aprendizado interativo e criativo. Se as tecnologias não evoluíssem, seria lógico que os agentes concentrassem as transações de sucesso e as considerassem como cálculos cartesianos.

Pavitt (1998) considera que a informação, as idéias e as descobertas científicas são os principais benefícios que a indústria recebe da academia e não são facilmente transmitidos. Essas contribuições contêm elementos variados que permitem o desenvolvimento da capacidade de resolução de problemas e envolve a transmissão de conhecimentos freqüentemente tácitos por meio da mobilização de pessoas e do contato face a face. Os benefícios tendem a ser geograficamente localizados.

Considerando esses elementos, podemos dizer que a inovação constitui-se de um processo interativo que traz, quase sempre, resultados inesperados e fomenta o conhecimento, e esse processo está ancorado na aprendizagem contínua, por ser ela também um produto da interação. Por isso faz-se necessário o fortalecimento das relações sociais, das interações contínuas que fomentem novas idéias.

As interações, provavelmente, ocupavam os pensamentos de Johnson e Lundvall (2000), quando afirmaram que o final do século $X X$ trouxe à tona dois fenômenos: o da globalização e o da localização, e a partir deles novas respostas organizacionais são necessárias, ao mesmo tempo em que se aponta a importância do crescimento do capital social e natural. Globalização significa que o governo nacional necessita procurar acordos com outros governos e organizações internacionais. Localização requer a cooperação com as comunidades locais e regionais. Nesse entrosamento, a importância do capital social é enfatizada.

Os sistemas de inovação localizados têm grande importância para a economia 
local, regional e nacional. Lawton-Smith (2003), estudando a relação entre a inovação e o desenvolvimento institucional, em uma perspectiva histórica, demonstra que o sistema local teve e tem uma grande influência política no crescimento da inovação regional e nacional.

A integração, peculiar a inovação localizada, promove a interação entre seus agentes, que, juntos, delineiam a forma e as ações dos sistemas. Quanto maior for essa integração, maior é a probabilidade de os sistemas de inovação estarem organizados em rede. A articulação em redes promove os agentes do sistema e o local em que se desenvolvem.

\section{REDE SOCIAL DO CONSÓRCIO DE} EXPORTAÇÃO: Compartilhamento de Informação e a Difusão do Conhecimento

A análise da rede social do Consórcio de Exportação possibilitou a configuração de sua rede, formada por 25 atores, cujas ações coletivas direcionam e efetivam as atividades desempenhadas no âmbito do consórcio, e possibilitou ainda, desvelar as relações que mobilizam a rede.

O diagrama da rede, Figura 1, evidencia a estrutura social da rede formada no domínio do Consórcio de Exportação, por meio das 101 ligações entre os 25 atores. Os atores, que atuam no nível estratégico (17) e operacional (8), são oriundos das indústrias de móveis, do sindicato local e do escritório do Consórcio. Neste estudo, eles foram identificados, durante toda a análise, por letras de "A" a " $Z$ ".

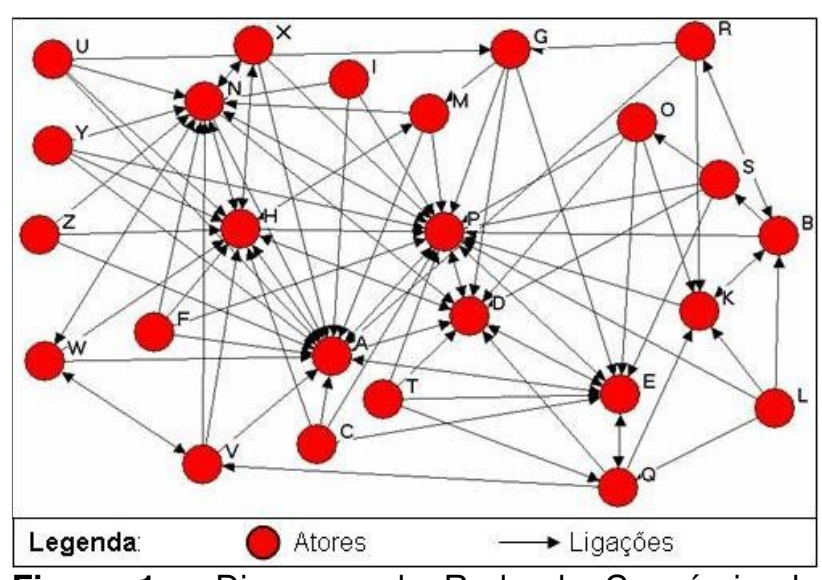

Figura 1 - Diagrama da Rede do Consórcio de Exportação

Dos 25 atores da rede, 17 são valorizados como contatos importantes, sendo o mais popular, ou seja, o que recebeu o maior índice de indicações - o "P" (Figura 1), seguido pelo "A", "H", "N", "D" e "E". O ator "P" recebeu 18 indicações; cerca de 75\% dos participantes do Consórcio o citaram como um contato importante. Ele obteve o dobro das indicações atribuídas ao ator "E", que ocupou a posição de quinto maior indicado. O ator "A", segundo maior indicado, foi apontado por $64 \%$ dos integrantes da rede, o "H" por 48\%, o "N" por $44 \%$, o "D" por $40 \%$ e o "E" por $36 \%$. A informação na rede social do Consórcio parece convergir, intensamente, para esses atores.

Esse grupo de atores, "P", "A", "H", "N", "D" e "E", coordena as atividades do consórcio e são líderes entre os consorcia- 
dos. As atividades desenvolvidas no consórcio são planejadas e gerenciadas por eles e pelo respeito que o grupo a eles devota é possível inferir que o compartilhamento da informação no grupo, na maior parte das vezes, é articulado por esses coordenadores, isto pode ser comprovado quando um dos entrevistados relatou algumas situações em que dissemina as atividades do consórcio aos participantes. A proximidade física dos consorciados intensifica o compartilhamento de informações e experiências.

A proximidade territorial das indústrias provoca algumas similaridades e adoção de estratégias comuns (STABER, 2001), que promovem a disseminação do conhecimento e inovações com características localizadas.

As indústrias do Consórcio, a exemplo do que ocorre em todo o Pólo Moveleiro, são bastante similares em termos de infra-estrutura, maquinários, processos de produção e, sobretudo, produto final, dentro de seus segmentos - estofados e madeira. Excetuando diferenças específicas de design e o fato de algumas indústrias direcionarem seus produtos para as classes sociais $A$ e $B$, a maior parte da produção, desse pólo, é destinada a classes mais populares. Essa semelhança foi explicitada pelos entrevistados.

O consórcio analisado é constituído por 17 indústrias do setor moveleiro, locali- zadas em um mesmo pólo moveleiro, que atuam nos segmentos de madeira e estofados. A Figura 2 ilustra a procedência dos atores em relação ao segmento industrial linha de madeira e linha de estofados e também de representantes do Consórcio de Exportação e do sindicato local.

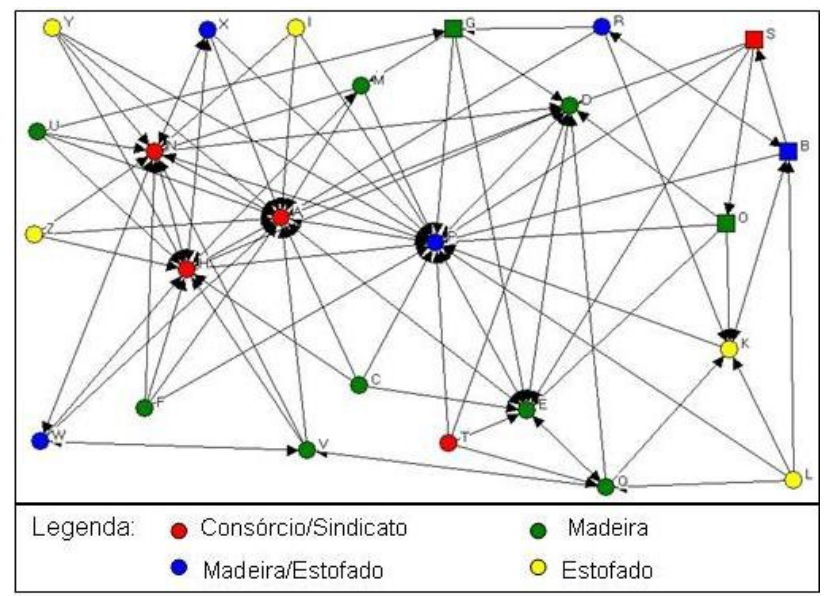

Figura 2 - Tipos de Móveis e Uso de Tecnologia

Dos 25 atores entrevistados, 10 pertencem a indústrias de móveis em madeira (verde), cinco de móveis estofados (amarelo), cinco a indústrias que fabricam móveis nos dois segmentos - madeira e estofados (azul) e cinco estão vinculados ao próprio consórcio e ao sindicato local (vermelho).

Observamos que, independente ao tipo de segmento a que o ator esteja vinculado, as informações são difundidas, principalmente, por e-mail; para ter acesso a essa informação, três atores dependem das secretárias e um do filho que trabalha com ele, isto em virtude de não dominarem as ferramentas de tecnologia da informação. Na Figura 2, esses atores estão representados por quadrado. Apesar de não 
acessarem diretamente a informação, mesmo assim, esses atores a recebem.

Um indicador importante para medir o alcance do compartilhamento da informação na rede é a distância geodésica. A distância geodésica - menor distância entre dois pontos - constitui-se na quantidade de atores - graus - pelos quais uma informação passa até atingir um outro ator (HANNEMAN, 2001).

A distância geodésica entre um ator e outro, na rede do Consórcio, vai de um a sete graus, sendo que a distância média entre os pares acessíveis é de aproximadamente 2,8 graus. Portanto, é possível um movimento máximo de sete etapas para que uma informação alcance $68 \%$ da rede, especialmente os representantes estratégicos. Isto significa que o compartiIhamento da informação na rede, alcança seus membros em um fluxo de informação conduzido por no máximo sete atores.

Esses dados são similares aos encontrados nas pesquisas de Milgram (1967) e Dodds, Muhamad e Watts (2003), que comprovaram que todas as pessoas podem ser alcançadas por até seis graus de separação. Isto denota que não importa o tamanho da população pesquisada, o resultado sempre é análogo. Ou seja, o fluxo da informação é regular e seu alcance é eficiente, visto que a difusão da informação na rede do consórcio tem o mesmo número de etapas de outros estudos, como os citados, conhecidos mundialmente.

Indicador similar ao de distância geodésica é o caminho geodésico - indica o número de caminhos possíveis pelo qual informação pode fluir. Alguns dos atores da rede do consórcio estão acessíveis por múltiplos caminhos, os atores que detêm um grande número de caminhos para outros atores, podem ter acesso à mesma informação por fontes distintas e têm maior probabilidade de receber uma informação do que um ator que tem apenas um canal aberto. O ator "D" possui 54 caminhos possíveis para o recebimento de informação na rede; isto significa que ele tem maior probabilidade, do que qualquer outro na rede, de receber uma informação que não flui livremente pela rede. Em seguida encontram-se os atores " $X$ " com 42 caminhos e o ator "H" com 41 caminhos.

Podemos considerar que a rede social do Consórcio de Exportação tem caminhos alternativos para a comunicação da informação, variando o índice de 30 até 54 caminhos. Hanneman (2001, p.53) afirma que se os atores têm apenas um caminho para transmitir uma informação, então a conexão com a rede é fraca, em virtude de ser carente de alternativas de fluxos de informação. Se, por outro lado, têm múltiplos caminhos para transmitir informações, então a conexão da rede é mais forte. 
Os atores que possuem múltiplos caminhos para compartilhar a informação, tanto recebem quanto disseminam mais informações pela rede. Ou seja, esse ator integra fluxos de informação na rede e por isso tem facilidade de comunicação com vários indivíduos na rede.

A proliferação da informação em grupos é comum nas redes, isto em virtude dos atores aproximarem-se de indivíduos que Ihes inspirem confiança, ou que tenham relações de amizade e em muitos casos relações profissionais também. A estrutura das redes constitui-se por grupos de atores.

Um grupo pode ser identificado pelas relações de reciprocidade, que propiciam o compartilhamento da informação e a construção do conhecimento na execução de uma atividade que, na visão de Molina (2003), constituem-se em uma comunidade.

O agrupamento de atores, em comunidades, possibilita o compartilhamento da informação e a absorção do conhecimento. Os grupos de atores que têm relações similares - maior coesão - são denominados de facção, aqui chamaremos, como Molina, de comunidade. Esse recurso possibilita a identificação de comunidades dentro da rede. Na Figura 3, observamos as comunidades da rede social do consórcio.

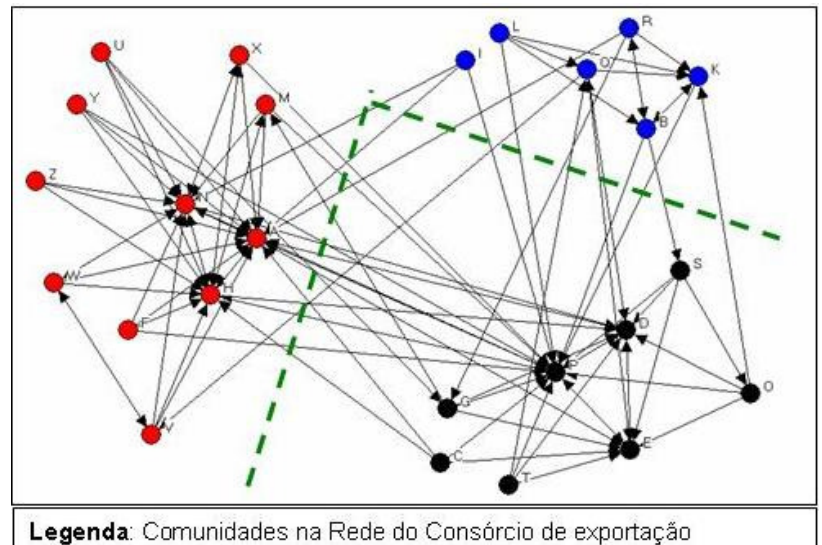

Figura 3 - Comunidades na Rede Social do Consórcio de Exportação

Observamos, claramente, três comunidades distintas. Duas - nas cores preta e azul - integram representantes estratégicos, e a comunidade na cor vermelha, majoritariamente, integram representantes operacionais; apenas dois representantes estratégicos pertencem a ela, um empresário (M) e um membro que atua na gerência do Consórcio (A).

Acreditamos que essas comunidades são movidas por interesses comuns: no grupo em azul prevalecem empresários do segmento de móveis estofados, no grupo em preto os integrantes são, proeminentemente, do segmento de madeira e no vermelho há a prevalência de técnicos administrativos que executam atividades operacionais nas indústrias e no escritório do Consórcio de Exportação.

Percebemos outros elementos aglutinadores que podem interferir na divisão dessas comunidades. Um deles são os relacionamentos de amizades que unem alguns dos empresários e o outro é a dire- 
toria do consórcio que reúne empresários líderes da rede. A comunidade em que relacionamentos de amizade foram evidenciados está representada na Figura $3 \mathrm{em}$ azul, e a ratificada pela gestão do Consórcio de Exportação está em preto.

Esses elementos, ao mesmo tempo em que os aproximam e os dividem em comunidades, intensificam o compartilhamento da informação e agilizam a difusão de experiências com riqueza de detalhes. $\mathrm{Na}$ comunidade (representada na Figura 3 em vermelho) em que há a prevalência de representantes operacionais, os resultados da pesquisa indicam que o compartilhamento da informação está enfatizado nos processos burocráticos para a exportação. Nas comunidades formadas majoritariamente por representantes estratégicos, o compartilhamento está centrado nos processos de gestão e isso as faz evoluir e buscar o aprimoramento.

Outra forma de difusão da informação e do conhecimento é por meio de pequenos grupos. Os cliques, que se constituem de grupos de atores que mantêm relações mais estreitas, ou seja, representam um subconjunto de uma rede em que os atores estão próximos e fortemente conectados. Os menores cliques são as díades (ligações de dois atores).
O mapa de uma rede, para Hanneman (2001), pode ser construído pela análise da composição de diferentes cliques, seus tipos e características dos agrupamentos, examinando seus tamanhos e a justaposição dos atores.

A rede social do Consórcio tem 22 cliques presentes em sua estrutura. Sete cliques são integrados por cinco atores cada, são os maiores da rede. Dez cliques possuem quatro integrantes cada, e cinco são formados por três atores cada. Todos os atores participam de pelo menos um clique. Isto denota que na rede todos pertencem a um grupo; de alguma forma um interesse comum os une e os aproxima. 


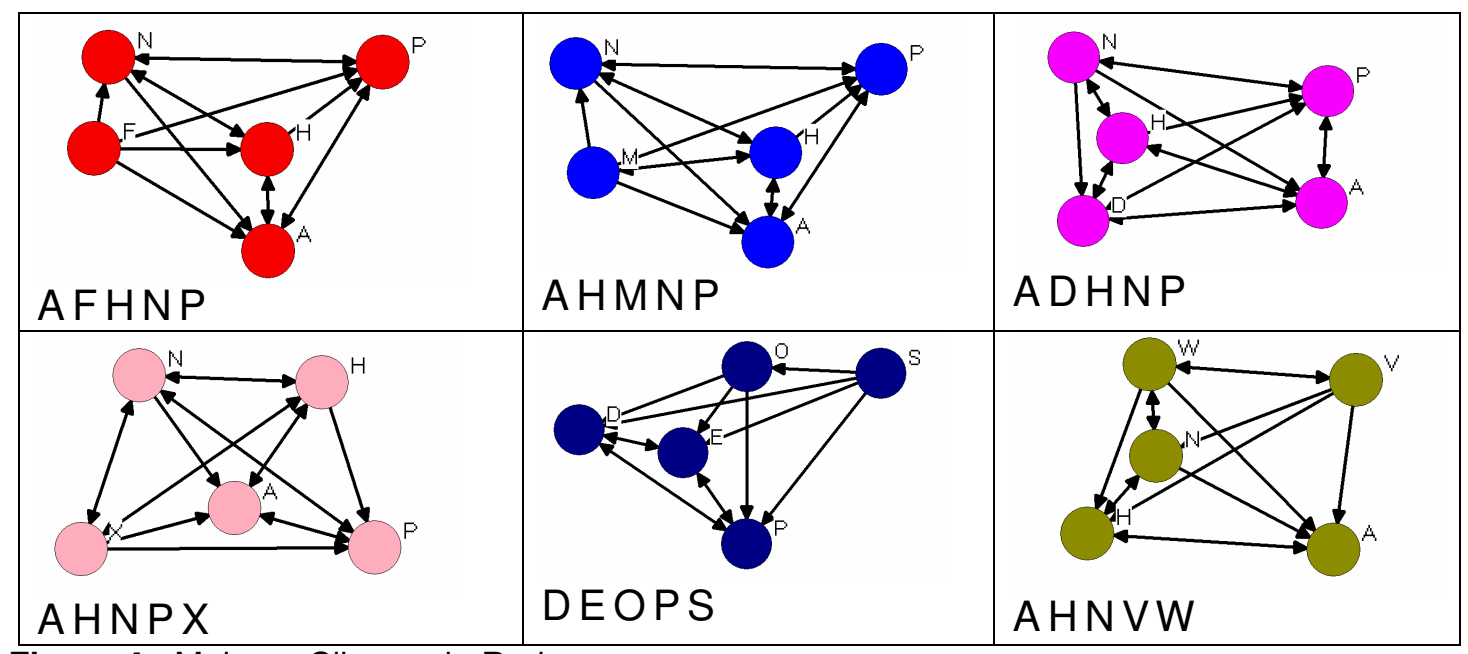

Figura 4 - Maiores Cliques da Rede

A Figura 4 representa os maiores cliques da rede. Dos atores mais influentes da rede, pelo menos três participam dos seis maiores. Essas inserções em cliques dos atores de maior influência acirram o compartilhamento da informação do consórcio para as empresas. Outro fator que contribui para o compartilhamento é a presença de um mesmo ator em vários cliques, situação que possibilita que a informação veiculada em um grupo alcance outro grupo.

A presença de representantes estratégicos em diversos cliques influencia também na difusão de informações sobre os processos de gestão desenvolvidos no consórcio e nas empresas.

Adotando os critérios desenvolvidos por Everett e Borgatti (1999) para medir a centralidade de grupos, identificamos, na rede do Consórcio, os grupos que são mais proeminentes, por meio da medida de centralidade de grau. Para os autores, as condições essenciais para medir a centralidade de um grupo são duas. A primeira por ser sempre derivada de medidas individuais existentes e a outra por enfatizar que qualquer medida aplicada a um grupo é uma generalização peculiar das medidas individuais correspondentes. Em síntese, a centralidade de um grupo é computada diretamente da rede de relacionamentos entre indivíduos e beneficia-se da possibilidade de trabalhar com justaposição nos grupos, podendo um indivíduo pertencer a vários grupos.

O clique dos atores - "A", "D", "H", "N", "P", em destaque na Figura 5 - tem um alto índice de centralidade em relação aos demais, o que demonstra que esse grupo tem um grande poder de mobilizar a rede para uma iniciativa específica, isso porque juntos comunicam-se com toda a rede, alcançando os níveis de atuação estratégico e operacional. Essa constatação 
reitera a influência e a importância desses atores, na rede.

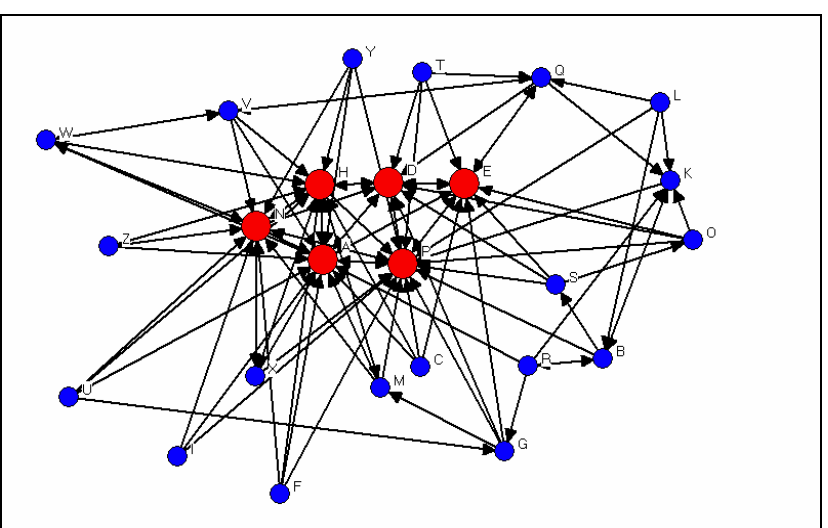

Figura 5 - Centralidade dos Cliques

Os atores que compõem o clique central por estarem ligados diretamente à gestão do consórcio, ou por serem representantes estratégicos das empresas ou por atuarem diretamente no escritório do consórcio, disseminam, com propriedade, os processos de gestão adotados pelo consórcio.

\section{INOVAÇÃO LOCALIZADA: Difusão dos Processos de Gestão do Consórcio de Exportação}

Percebemos, nas entrevistas, que existe uma similaridade em alguns dos produtos, na qualidade dos processos desenvolvidos, equipamentos, design, etc. Quanto à similaridade dos design os entrevistados chegaram até a nomeá-los de design tradicional "aquele que todo mundo tem" (Entr. C).

As indústrias que compõem o Consórcio de Exportação já eram similares antes de sua criação, em relação à infraestrutura, entre si e com outras indústrias do pólo. A parceria formada pelas 17 indústrias para o consórcio de exportação não contribuiu para a inovação localizada nos aspectos citados.

Entretanto, é inegável a disseminação e a absorção do conhecimento entre as indústrias do Consórcio de Exportação no que concerne à inovação de gestão. A inovação de gestão, também denominada inovação organizacional, é caracterizada pela introdução de expressivas melhorias nos processos pertinentes à gestão da organização (HIGGINS, 1995; LASTRES, FERRAZ, 1999).

Inconteste é o fato de que as indústrias investigadas estão preocupadas com novas formas de gestão. A nossa visão a respeito dessas indústrias, formada pela literatura, era de que elas empregavam processos retrógrados, e muito conservadores em relação às novas tecnologias. Ao invés, encontramos uma grande parte de empresas contemporâneas, com tecnologias de gestão e negócios consoantes com os disseminados nos últimos tempos.

Entre as empresas, de modo geral, encontramos duas formas distintas de visão e gestão dos negócios: as empresas tradicionais e as orientadas para os processos (HAMMER, 1998). As orientadas para os processos, ao que parece, são as formas de gestão mais comuns entre as empresas participantes do Consórcio de Exportação. Geralmente, essas empresas 
têm planos de ações bem definidos e sabem bem aonde querem chegar. Os processos que desenvolvem são cuidadosamente projetados e avaliados.

O Consórcio de Exportação tem um plano de negócios bem definido e projetado para os próximos dez anos, plano que é compartilhado e revisto periodicamente por todos os empresários participantes - estratégicos. Tal forma de condução do consórcio pode ter sido disseminada entre os empresários que levaram para suas empresas esse modelo de gestão. Isso é visível quando comparado o discurso dos empresários sobre a forma como conduzem suas empresas e a condução do consórcio. Além do quê, a estrutura das empresas constituída por pessoas em cargos de responsabilidades; orientadas por reuniões para integração e compartilhamento; com portas abertas para todos e com considerável valorização dos seus fluxos informacionais - nos leva a crer que os empresários estão preocupados em incorporar novas técnicas organizacionais e de gestão, que é uma das formas de inovação que Vargas e Alievi (2000) imputam à indústria moveleira.

As principais formas de apropriação do conhecimento para a inovação de gestão que identificamos pelas entrevistas foram, especialmente, os processos e produtos desenvolvidos para a gestão do Consórcio de Exportação, como: catálogo de produtos, com fotos e especificações detaIhadas, em três idiomas - português, inglês e espanhol; metodologia para formação de preços e cálculo de custos; apresentação da tabela de preços; logística; comunicação eletrônica; visão comercial e de mercado; formas de comercialização, entre outros procedimentos administrativos.

A participação no Consórcio de Exportação e a convivência com uma nova dinâmica na condução da gestão empresarial provocaram uma reflexão e comparação com a condução dos processos organizacionais internos de suas indústrias, o que levou os empresários a desenvolverem inovações nos processos de gestão.

Observamos, ainda, que a adoção de inovações de gestão foi inspirada, também, pelo entendimento e conhecimento absorvidos pelo compartilhamento das práticas organizacionais entre os empresários. Os comentários dos empresários, a seguir, evidenciam e exemplificam essa situação.

Às vezes, aparecem algumas idéias interessantes para serem aplicadas aqui e uma das coisas que nós queremos mudar aqui, principalmente para os produtos de exportação, é a nossa embalagem que hoje é uma caixa de papelão e não tem mais nada protegendo em cima da caixa. Têm empresas, que estão dentro do Consórcio, que usam, além do papelão, um plástico para proteger da umidade e dar uma segurança maior, uma proteção maior, nós estamos querendo adotar um sistema similar a esse também (Entr. F).

A gente sempre buscou estar um 
pouco à frente. $O$ que não quer dizer que estamos em todas as áreas à frente de outras empresas, acho que muita coisa tem que ser feita, mas eu diria o seguinte: a gente está buscando estar sempre internalizando conhecimento - apologia! Mesmo assim, algumas coisas de alguma forma interferem nos nossos procedimentos. Houve algumas alterações em função disso, eu acho que principalmente nessa área de comunicação, que a gente está tentando buscar competência na área e também procedimentos administrativos. O que às vezes não era dado o devido valor, hoje a gente tem buscado melhorar também isso e com certeza são conseqüências desse relacionamento com as empresas que atuam com a gente no Consórcio, das novas necessidades (Entr. E).

O Consórcio aproximou as empresas e acho que essa interação, essa aproximação tem deixado as empresas um pouco mais similares, especialmente nas áreas administrativa e de comercialização, de visão de mercado (Entr. E).

Essa realidade, apresentada pelas citações dos empresários nas entrevistas, tem seu expoente na credibilidade do Consórcio de Exportação e das indústrias parceiras. O sucesso dos negócios fortalece as interações que despertam admiração e confiança mútuas e faz com que as empresas ascendam a um patamar superior de competência e criem novas necessidades organizacionais, que as impulsionam a se capacitar sempre mais.

Constatamos que os empresários das indústrias investigadas estão preocupados com a forma como gerenciam seus negócios, devido a isso absorvem conhecimen- tos de seus parceiros e do consórcio e os aplicam, tornando suas empresas similares, sobretudo nas questões referentes à gestão de seus negócios. O conhecimento é aplicado nas empresas investigadas, com maior ênfase na comunicação eletrônica, na forma de comercialização, nos materiais promocionais e de venda, na metodologia empregada de custos e preços, na logística, entre outras formas de gestão. A apropriação e a aplicação do conhecimento resultam na inovação localizada de gestão.

A inovação localizada é resultante do compartilhamento da informação e da construção do conhecimento; bem como da proximidade e da interação entre as organizações, que criam elos que as levam a modificações conjuntas, similares e sinérgicas que refletem no setor e no seu ambiente e podem determinar o direcionamento dos processos industriais.

O estudo da inovação localizada no âmbito do Consórcio culminou em um processo (Figura 6) que, primeiramente, estimula uma mudança nas empresas e, em seguida, levam-nas a buscar competências para sentirem-se parte de algo maior e, nesse movimento, ocorre a inovação localizada em que as empresas, no caso as vinculadas ao Consórcio, desenvolvem inovações similares. A Figura 6 ilustra esse processo relacionado ao contexto socioeconômico e cultural das empresas. 


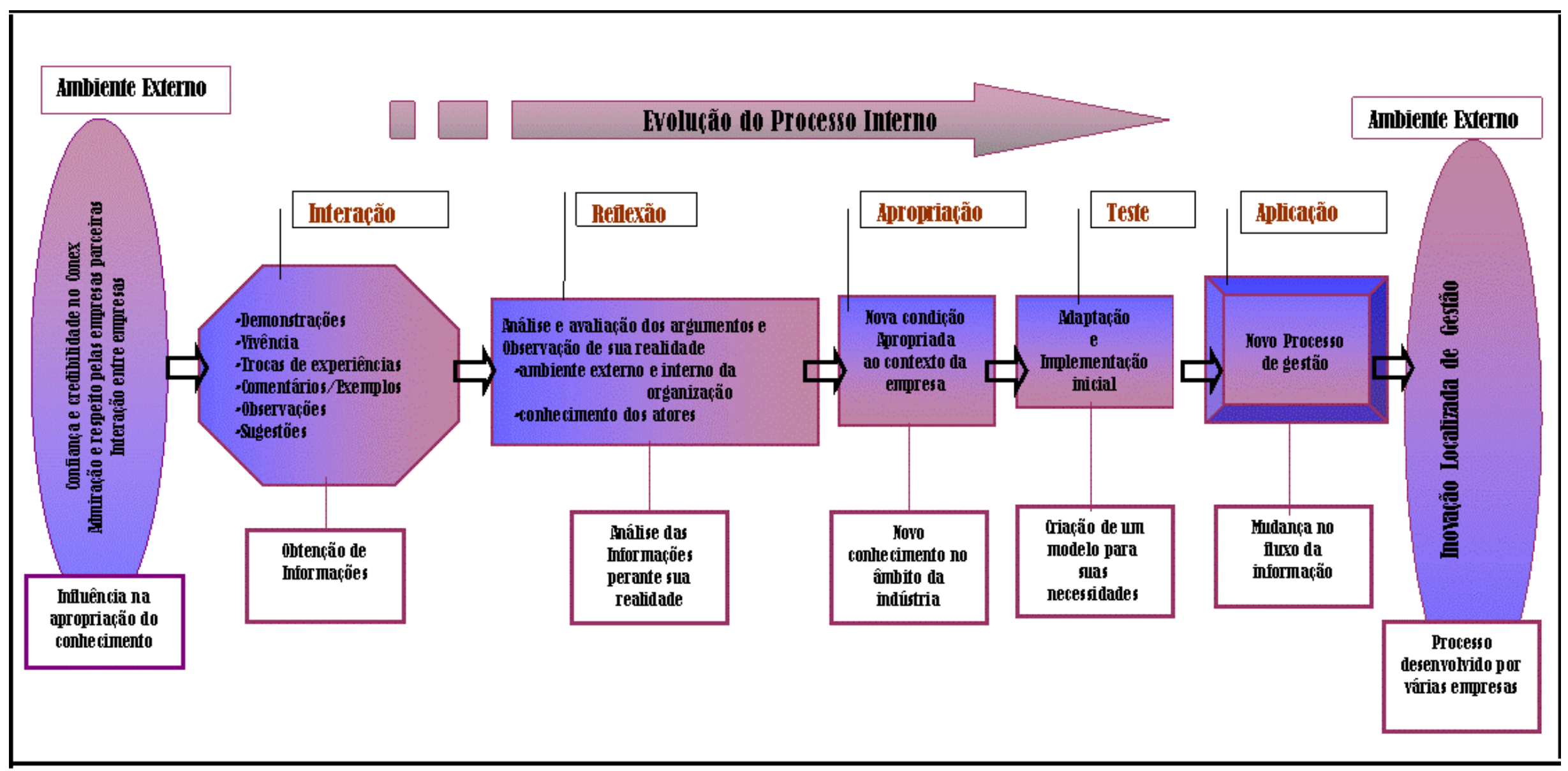

Figura 6-Da Apropriação do Conhecimento a Inovação Localizada de Gestão 
A Figura 6 demonstra o processo de inovação localizada das indústrias vinculadas ao Consórcio e delimita seu início com a interação - em rede - entre os empresários, na qual ocorre o compartilhamento da informação. Valendo-se da análise das entrevistas, nossa percepção evidencia que, para o compartilhamento, é necessário que o relacionamento entre os empresários seja fundamentado no respeito, na confiança e na admiração; sem esses elementos, a informação perde referência. Assim, vemos que, para a apropriação do conhecimento, a credibilidade dos pares e do ambiente do qual afluem às informações são fundamentais, além de constituírem meios de influência para o sucesso desse processo.

A interação entre os empresários, que resulta na obtenção de informações, é freqüente nas reuniões do Consórcio, o que possibilita o compartilhamento. Esse compartilhamento ocorre desde a recepção dos consorciados, momento em que trocam idéias e experiências, até no desenvolvimento da pauta da reunião, na qual há a oportunidade para demonstrações dos trâmites administrativos e comerciais do Consórcio. É importante assinalar que a troca de informações, no decorrer da reunião, é contínua, tanto pelos comentários, exemplos e discussões dos projetos que envolvem todo o grupo, quanto por obser- vação que, para alguns, resultam em ações. O grupo de empresários que participa do Consórcio criou ligações, com base nessa parceria, que os aproximou também fora do Consórcio. Um dos indícios dessa aproximação são os encontros e contatos mantidos freqüentemente, graças aos quais eles aproximam suas realidades e trocam experiências mais singulares.

A interação, que movimenta as redes sociais, é condutora do compartilhamento da informação e da difusão do conhecimento. No Consórcio de Exportação estudado os grupos - as comunidades e as cliques - intensificam o compartilhamento da informação por demonstrações, visitas, trocas de experiências, entre outras formas de compartilhamento. Além da constatação de que a informação alcança todos os atores estratégicos - empresários - na rede (distância geodésica), situação que intensifica e qualifica as interações. As redes sociais têm papel determinante no processo de inovação localizada, é por ela que ocorre a obtenção da informação.

Tem, também, atribuição importante, nesse processo, a análise dos ambientes externo e interno - da indústria: fornecedores, consumidores, espaço territorial, porte empresarial, concorrentes, volume dos negócios, cultura organizacional, nível de conhecimento e ativos que encerram formas comuns que favorecem a apropriação do 
conhecimento e à efetiva implantação de processos, entre outras peculiaridades. Sob esses aspectos, as informações obtidas são avaliadas - processo de reflexão - e, com base em sua realidade, há uma transformação da condição inicial em que um conhecimento específico às necessidades da indústria é criado.

Para uma indústria, em particular, esse é um novo conhecimento - apropriação -, que precisa ser adaptado para ser implantado dentro das circunstâncias existentes. É necessário testar a funcionalidade, do novo processo de gestão, para sua implantação, de fato, para que atenda às demandas e possibilite novos aportes à indústria. A aplicação do novo processo de gestão constitui-se em uma inovação para a indústria que o incorporou e ocasiona uma mudança no fluxo da informação.

A conjunção desse processo por muitas indústrias, como pelas indústrias do grupo que compõem o Consórcio, causa a inovação localizada, no caso, inovação de gestão.

Muitos são os agentes que podem contribuir para a inovação localizada. Participaram, especialmente, desse processo: o Consórcio; as indústrias; diversos materiais de informação, que foram fontes importantes na geração das primeiras inovações - ainda no âmbito do Consórcio; bem como organizações que disseminam o conhecimento e informação e, sobretudo, os resultados advindos da interação espontânea entre os empresários - sua rede social.

\section{CONSIDERAÇÕES FINAIS}

A interação entre os membros do Consórcio originou uma estrutura de indivíduos e relações que formam uma rede interdependente capaz de ligá-los em todos os aspectos e decisões que envolvem o Consórcio. A pluralidade de relações criou ligações, que a princípio eram frágeis, mas se fortaleceram com ações e intervenções de seus líderes, consolidando o grupo, sua ação social e levando as lideranças a procurar atender as exigências mútuas socialmente produzidas.

O processo de socialização no âmbito do consórcio, coerente com as transformações socioculturais, abriu-se para a diversidade de mecanismos e formas de relacionamento. A multiplicidade de caminhos e a valorização das ligações são evidentes, especialmente entre os líderes que sobressaíram no mapeamento da rede social. Percebemos até uma sincronização de idéias e condutas, desses líderes, em prol da consolidação da estrutura social que dá sustentação a essa aliança.

As relações mais próximas na rede, tanto de negócios quanto de amizade, são ligações fortes que favorecem o compartiIhamento da informação e a construção do conhecimento. 
O compartilhamento da informação e a construção do conhecimento na rede social do Consórcio de Exportação estudado, fez emergir um processo de inovação localizada, entre as empresas que formam o consórcio, a partir das interações mantidas na rede. A reflexão, decorrente do compartilhamento da informação, constitui-se a próxima etapa do processo, que envolve a análise e a avaliação dos argumentos, tendo como base o ambiente organizacional. A conseqüente apropriação do conhecimento está alicerçada no aperfeiçoamento das práticas sociais e culturais da organização. Sua funcionalidade é testada e, em seguida, é desenvolvido um modelo adequado às necessidades organizacionais. $A$ aplicação desse modelo gera um novo processo de gestão e o redirecionamento do fluxo da informação de acordo com a nova situação redesenhada. Esse processo, quando desenvolvido por várias organizações, gera a inovação localizada.

A difusão da informação e do conhecimento em redes sociais influencia processos e ações em que a interação permeia esse espaço o tempo todo; trata-se de um processo permanente, recomeça constantemente. É esse processo que possibilita a inovação localizada.

O espaço transcultural - 0 das redes - faz que um ator seja importante em um momento e, que em um segundo momento, ocupe outra posição, menos central ou secundária na rede. $O$ espaço social permite o desvelamento de temas e projetos pessoais e profissionais que, no âmbito organizacional, não seriam possíveis. espaço econômico cria novas formas organizacionais e de inserção no mercado. Enfim, pela interação, as redes renovam-se em espaços de criação e apropriação e se fortalecem, pelas parcerias, para buscar e ampliar diferentes inserções comerciais e/ou produtivas.

\section{REFERÊNCIAS}

BARNES, J. A. Social networks. AddisonWesley Module in Anthropology, Reading, MA, v.26, p.1-29, 1972.

BORGATTI, Stephen P.; EVERETT, Martin G; FREEMAN, L.C. UCINet 6 for Widows: Software for social network analysis. Harvard, MA: Analytic Technologies, 2002.

BRASIL. Lei no 10.973 de 2 de dezembro de 2004. Diário Oficial [da] República Federativa do Brasil, Brasília, DF, dez. 2004.

CASSIOLATO, José Eduardo; LASTRES, Helena Maria Martins. Sistemas de inovação: políticas e perspectivas. Parcerias Estratégicas, Brasília, n. 8, p. 237-255, maio 2000. Disponível em:

$<$ http://www.mct.gov.br/CEE/revista/Parceri as8/cassiolato.PDF>. Acesso em: 17 out. 2003.

CROSS, Rob; BORGATTI, Stephen P.; PARKER, Andrew. Making invisible work visible: using social network analysis to support strategic collaboration. California Management Review, Berkeley, CA, v.44, n.2, p.25-46, 2002.

CROSS, Rob; PRUSAK, Laurence; PARKER, Andrew. Where work happens: the care and feeding of informal networks 
in organizations, 2002. Disponível em:

$<$ http

://www3.boulder.ibm.com/services/learning/ solutions/ideas/whitepapers/iko wwh.pdf>. Acesso em: 21 abr. 2003.

DODDS, Peter Sheridan; MUHAMAD, Roby; WATTS, Duncan J. An experimental study of search in global social networks. Science, Washington, US, v.301, p.827829, 8 Aug. 2003.

EVERETT, Martin G.; BORGATTI, Stephen $P$. The centrality of groups and classes. Journal of Mathematical Sociology, London, GB, v.23, n.3, p.181-201, 1999.

FLEURY, Afonso; FLEURY, Maria Tereza Leme. Aprendizagem e inovação organizacional: as experiências de Japão, Coréia e Brasil. 2.ed. São Paulo: Atlas, 1997.

GARTON, Laura; HAYTHORNTHWAITE, Caroline; WELLMAN, Barry. Studying online social networks. JMC - Journal of Computer-Mediated Communication, Bloomington, IN, v.3, n.1, Jun.1997. Disponível em: <http://www. ascusc.org/jcmc/vol3/issue1/garton.html>. Acesso em: 21 jun. 2003.

HAMMER, Michael. A empresa voltada para processos. HSM Management, São Paulo, v.2, n.9, p.6-9, jul./ago. 1998.

HANNEMAN, Robert A. Introduction to social network methods. 2001. Disponível em: <http://faculty.ucr.edu/ hanneman/SO C157/NETTEXT.PDF>. Acesso em 26 ago. 2003.

HIGGINS, James M. Innovate or Evaporate: test and improve your organization's IQ - Its Innovation Quotient. Winter Park, FL: The New Management, 1995.

JOHNSON, Björn; LUNDVALL, Bengt-Åke. Promoting innovation systems as a response to the globalising learning economy. In: CASSIOLATO, José Eduardo; LASTRES, Helena M.M. Arranjos e Sistemas Produtivos Locais e as Novas Políti- cas de Desenvolvimento Industrial e Tecnológico. Rio de Janeiro: IE/UFRJ, 2000. Disponível em: $<$ http://www.druid.dk/sumer2000/Gallery/nyi ohnson\&lundvall.pdf>. Acesso em: 13 out. 2003.

KOHN, Ruth Canter. A noção de rede. Capítulo traduzido por Nilda Alves. In: CHARLOT, Bernard (Coord.). L école et le territoire: espaces, nouveaux enjeux. Paris: Armand Colin, 1994. Cap. 7.

LASTRES, Helena M.M.; FERRAZ, João Carlos. Economia da informação, do conhecimento e do aprendizado. In:

LASTRES, Helena M.M.; ALBAGLI, Sarita (Orgs.). Informação e globalização na era do conhecimento. Rio de Janeiro: Campus, 1999. cap.1, p.27-57.

LAWTON-SMITH, Helen. Knowledge Organizations and Local Economic Development: The Cases of Oxford and Grenoble. Regional Studies, Cambridge, GB, v.37, n.9, p.899-909, Dec.2003.

LUNDVALL, Bengt-Åke. National systems of innovation: towards a theory of innovation and interactive learning. London: Pinter, 1995.

MARTELETO, Regina Maria. Análise de Redes sociais: aplicação nos estudos de transferência da informação. Ciência da Informação, Brasília, DF, v.30, n. 1, p. 7181, jan./abr. 2001.

MARTELETO, Regina Maria. Redes e configurações de comunicação e informação: construindo um modelo interpretativo de análise para o estudo da questão do conhecimento na sociedade. Investigación Bibliotecológica, México, v.14, n.29, p.6994, jul./dic. 2000.

MILGRAM, S. The small world problem. Psychology Today, New York, v.6, n.1, p.62-67, 1967.

MITCHELL, Clyde J. Social Networks. Annual Review of Anthropology, Palo Alto, 
v.3, p.279-299, Jan.1974.

MOLINA, José Luis. Como identificar comunidades de práticas. [Madri: Redíris], [2003]. Disponível em: <http://revistaredes.rediris.es/webredes/coops.htm>. Acesso em: jan. 2005.

PAVITT, Keith. Sectoral patterns of technical change: towards a taxonomy and a theory. Research Policy, Amsterdam, NL, v.13, n.6, p.343-373, Dec.1984.

PAVITT, Keith. The social shaping of the national science base. Research Policy, Amsterdam, NL, v.27, n.8, p.793-805, 1998.

STABER, Udo. The Structure of networks in Regional Science. International Journal of Urban and Regional Research, Oxford, v.25, n.3, p.537-552, 2001.

VARGAS, Marco Antonio; ALIEVI, Rejane Maria. Competitividade, capacitação tecnológica e inovação no Arranjo Produtivo Moveleiro da Serra Gaúcha. Rio de Janeiro: IE/UFRJ, 2000. (Nota Técnica, 39). Disponível em: <http://redesist.ie.ufri.br/nts/nt2/NT39.PDF> Acesso em: 23 mar. 2003.

Maria Inês Tomaél

Professora do Departamento de Ciência da Informação da UEL, doutora em Ciência da Informação pela UFMG.

\section{Title}

Social networks, knowledge and localized innovation

\section{Abstract}

The process of innovation is influenced by its environment, which makes it dependent on social interaction, a preponderant factor for its growth and solidification. Social networks, framed by the interactions among actors, provide information sharing and knowledge building, determining aspects for the development of innovations. Considering such elements, the objective of this study was to distinguish innovation and knowledge experiences of localized nature in furniture export consortium. To do so, Social Network Analysis (SNA) was the methodology employed, for it charts the interactions among actors, giving emphasis to information measures and flows among them. The results indicate that social networks pervade the information sharing that leads to knowledge acquirement and its adaptation to distinct realities, and that such process occurs in the midst of the consortium participating companies in the process management field of action. Those companies develop similar procedures aiming management innovation. Due to that, we consider consortium social network management innovation to be localized.

\section{Keywords}

Social Networks; Information Sharing; Localized Innovation

\section{Título}

Redes sociales, conocimiento e innovación localizada

\section{Resumen}

El proceso de innovación recibe influencia de su medio, lo que lo hace dependiente de la interacción social, que es preponderante para su crecimiento y solidificación. Las redes sociales, estructuradas por las interacciones entre actores, hacen posible compartir la información y la construcción del conocimiento, determinantes para el desarrollo de las innovaciones. Considerando esos elementos, el objetivo de este estudio fue distinguir experiencias de carácter localizado de la innovación y del conocimiento en un consorcio de exportación de muebles. Para esto, la metodología empleada fue el Análisis de Redes Sociales (ARS), que 
mapea las interacciones entre los actores, enfatizando medidas y flujos de información entre ellos. Los resultados indican que las redes sociales permiten compartir la información, lo que lleva a la apropiación del conocimiento y su adaptación para distintas realidades y que ese proceso ocurre entre las compañías participantes del consorcio en el ámbito de gestión de procesos. Tales compañías desarrollan procedimientos similares para la innovación de gestión. Dado este hecho, consideramos que en la red social del consorcio la innovación de gestión es localizada.

\section{Palabras Clave}

Redes Sociales; Compartir la Información; Innovación Localizada. 